\title{
Effect of preoperative segmental range of motion on patient outcomes in cervical disc arthroplasty
}

Ting-kui Wu${ }^{\dagger}$, Hao Liư, Chen Ding, Xin Rong, Jun-bo He, Kang-kang Huang, Ying Hong and Bei-yu Wang ${ }^{*}$

\begin{abstract}
Background: Cervical disc arthroplasty (CDA) has been demonstrated, in clinical trials, as an effective and safe treatment for patients diagnosed with radiculopathy and/or myelopathy. However, the current CDA indication criteria, based on the preoperative segmental range of motion (ROM), comprises a wide range of variability. Although the arthroplasty level preserved ROM averages $7^{\circ}-9^{\circ}$ after $C D A$, there are no clear guidelines on preoperatively limited or excessive ROM at the index level, which could be considered as suitable for CDA.
\end{abstract}

Methods: This was a retrospective study of patients who underwent CDA between January 2008 and October 2018 using Prestige-LP discs in our hospital. They were divided into the small-ROM $\left(\leq 5.5^{\circ}\right)$ and the large-ROM $\left(>12.5^{\circ}\right)$ groups according to preoperatively index-level ROM. Clinical outcomes, including the Japanese Orthopedics Association (JOA), Neck Disability Index (NDI), and Visual Analogue Scale (VAS) scores, were evaluated. Radiological parameters, including cervical lordosis, disc angle (DA), global and segmental ROM, disc height (DH), and complications were measured.

Results: One hundred and twenty six patients, with a total of 132 arthroplasty segments were analyzed. There were 64 patients in the small-ROM and 62 in the large-ROM group. There were more patients diagnosed with cervical spondylosis in the small-ROM than in the large-ROM group $(P=0.046)$. Patients in both groups had significantly improved JOA, NDI, and VAS scores after surgery, but the intergroup difference was not significant. Patients in the small-ROM group had dramatic postoperative increase in cervical lordosis, global and segmental ROM $(P<0.001)$. However, there was a paradoxical postoperative decrease in global and segmental ROM in the large-ROM group postoperatively $(P<0.001)$. Patients in the small-ROM group had lower preoperative $\mathrm{DH}(P=0.012)$, and a higher rate of postoperative heterotopic ossification $(\mathrm{HO})(P=0.037)$.

Conclusion: Patients with preoperatively limited segmental ROM had severe $\mathrm{HO}$, and achieved similar postoperative clinical outcomes as patients with preoperatively excessive segmental ROM. Patients with preoperatively limited segmental ROM showed a postoperative increase in segmental mobility, which decreased in patients with preoperatively excessive segmental ROM.

Keywords: Cervical disc arthroplasty, Range of motion, Segmental mobility, Limited motion, Excessive motion

\footnotetext{
* Correspondence: dove-baker@163.com

${ }^{\dagger}$ Ting-kui Wu and Hao Liu are contributed equally to this work and should be considered co-first authors.

Department of Orthopedic Surgery, West China Hospital, Sichuan University

No. 37 Guo Xue Rd, Chengdu 610041, Sichuan, China
}

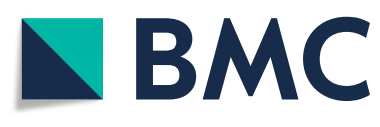

(c) The Author(s). 2020 Open Access This article is licensed under a Creative Commons Attribution 4.0 International License, which permits use, sharing, adaptation, distribution and reproduction in any medium or format, as long as you give appropriate credit to the original author(s) and the source, provide a link to the Creative Commons licence, and indicate if changes were made. The images or other third party material in this article are included in the article's Creative Commons licence, unless indicated otherwise in a credit line to the material. If material is not included in the article's Creative Commons licence and your intended use is not permitted by statutory regulation or exceeds the permitted use, you will need to obtain permission directly from the copyright holder. To view a copy of this licence, visit http://creativecommons.org/licenses/by/4.0/ The Creative Commons Public Domain Dedication waiver (http://creativecommons.org/publicdomain/zero/1.0/) applies to the data made available in this article, unless otherwise stated in a credit line to the data. 


\section{Introduction}

In recent decades, cervical disc arthroplasty (CDA) has been studied in many clinical trials as an alternative surgical treatment to anterior cervical discectomy and fusion (ACDF), due to a paradigm shift towards preserving motion and avoiding adjacent segment disease [1-7]. Segmental range of motion (ROM) has been commonly accepted, in published FDA-approved trials, as an indication for using CDA. These trials suggest that preoperative segmental ROM should range between $2^{\circ}$ to $11^{\circ}$ or $2^{\circ}$ to $20^{\circ}$ on lateral flexion-extension X-rays [4-9], presenting patients who have undergone CDA with a wide range of variability in segmental motion. There are no clear guidelines as to the optimal preoperative indexlevel ROM; although the preoperative ROM at the index level averaged $7^{\circ}-9^{\circ}$, and a similar motion was successfully preserved after surgery [10-14]. These observations raise a question for surgeons; whether limited or excessive preoperative ROM, other than the average one at the index level, could also achieve satisfactory clinical or kinematic outcomes?

There is limited data to answer the question above. $\mathrm{Tu}$ et al. [10] concluded that preoperatively less-mobile patients $\left(\mathrm{ROM} \leq 5^{\circ}\right)$ had similar clinical improvements, but showed a greater increase in segmental mobility than more-mobile $\left(\mathrm{ROM}>5^{\circ}\right)$ patients. However, some patients in the more-mobile group had excessive segmental ROM that may affect the results. To our knowledge, no clinical study on CDA has specifically analyzed patients with preoperatively excessive ROM at the index level. Patients selection is crucial to guarantee all the benefits of CDA. This study aims to investigate the influence of preoperative index-level ROM on postoperative ROM after CDA, and whether the patients with preoperatively limited or excessive segmental ROM are suitable candidates for arthroplasty.

\section{Methods \\ Patients}

Patients (312) who underwent CDA or hybrid surgery (HS) in the West China Hospital of Sichuan University, using Prestige-LP discs between January 2008 and October 2018, were retrospectively reviewed. The surgical indications were intractable symptomatic radiculopathy and/or myelopathy caused by cervical degenerative disc disease (DDD) or spondylosis at 1-or 2-levels, from C3C7. Exclusion criteria for arthroplasty were: 1) severe facet joint degeneration, 2) ossification of the posterior longitudinal ligament (OPLL), 3) segmental ROM $<2^{\circ}$, 4) segmental instability ( $>3.5 \mathrm{~mm}$ sagittal plane translation or $>20^{\circ}$ sagittal plane angulation), 5) intervertebral disc height loss more than 50\% and, 6) less than 12 months follow-up period. ACDF was performed if radiographic signs of instability, bridging osteophytes, and severe facet degeneration were observed in the 2-level disease. The study protocol was approved by the institutional ethics committee, and all patients signed informed consent.

\section{Cutoff values for preoperative segmental ROM}

There is no consensus on cutoff values for relatively small or large ROM at the index level for surgery. Tu et al. [10] divided patients based on C5/6 preoperative ROM of $\leq 5^{\circ}$ and $>5^{\circ}$, without explanation. Kang et al. [15] defined cutoff values as $10^{\circ}$, to group patients according to the average segmental ROM at the last follow-up. In the current study, the mean and standard deviation (SD) of radiographic data of the segmental ROM at the index levels, were calculated. Each target disc in 2-level CDA surgery was considered as an independent data point. The data were normally distributed around the mean of $9.01^{\circ}$ with an SD of $3.47^{\circ}$ (K-S test, $P=0.200)$. Based on the raw data, the cutoff values for preoperative small ROM were defined as mean - SD, while large $\mathrm{ROM}$ was mean $+\mathrm{SD}$. Therefore, the smallROM group was defined as having segmental ROM of $\leq 5.5^{\circ}$ at the index level (Fig. 1) and the large-ROM group as $>12.5^{\circ}$ (Fig. 2).

\section{Surgical techniques}

All operations were carried out by the same senior surgeon (H.L.). A standard right-sided anterior cervical approach was performed after general anesthesia. Thorough decompression was done at the index levels by removing the disc tissue, posterior longitudinal ligament, and osteophytes to achieve neural decompression. Appropriated Prestige-LP disc (Medtronic Sofamor Danek, Memphis, Tennessee) or Zero-P implant (Synthes, Oberdorf, Switzerland) was inserted into the intervertebral space after the endplates were well prepared. Then, C-arm fluoroscopy was performed to verify the proper placement of the implants. A drainage tube was inserted after irrigation and hemostasis before the closure of the incision.

\section{Data collection}

The clinical and radiographic outcomes of patients were routinely evaluated at regular intervals: before surgery, at 1 week, 3, 6, 12 months postoperatively, and at the last follow-up. Clinical outcomes were evaluated according to validated self-assessment questionnaires, including the Japanese Orthopedics Association (JOA), Visual Analogue Scale (VAS), and Neck Disability Index (NDI) scores. Radiological parameters including cervical lordosis, disc angle (DA) of the arthroplasty segments, ROM of C2 - C7 and the arthroplasty segments, and disc height (DH) were measured in lateral radiographs in neutral, extension and flexion views. Global and segmental ROMs were defined 

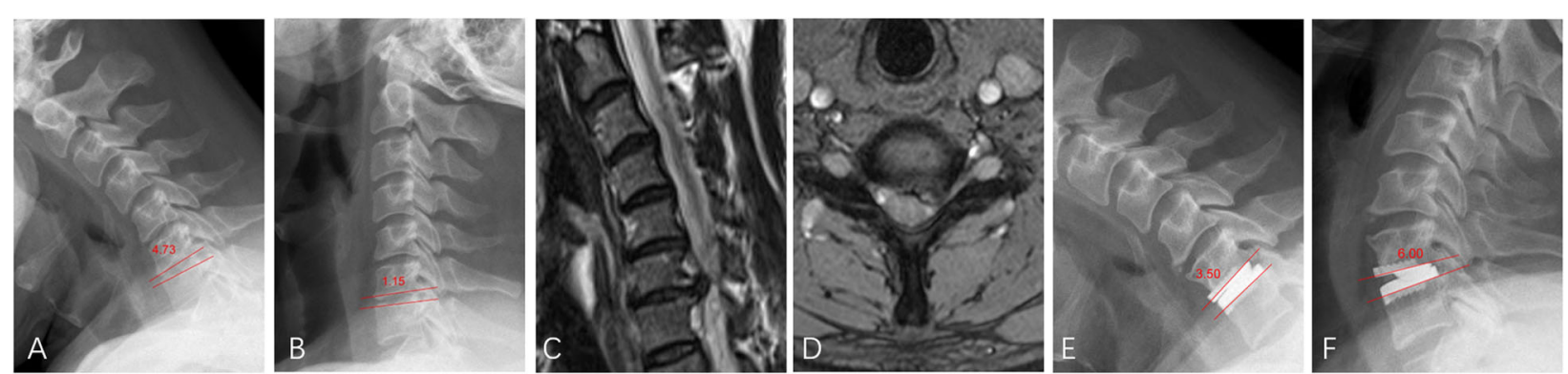

Fig. 1 A patient underwent CDA at C6/7 using Prestige-LP discs in the small-ROM group. Preoperative segmental ROM was measured at 3.48 using lateral flexion-extension X-rays ( $\mathbf{a}$ and $\mathbf{b}$ ). Preoperative MRI demonstrated disc herniation at C6/7 (c and $\mathbf{d}$ ). X-rays at 50 months follow-up (e and $\mathbf{f}$ ) showing increased segmental mobility $\left(\mathrm{ROM}=9.50^{\circ}\right)$ at the arthroplasty segment

as the difference in respective Cobb angles between flexion and extension views. We applied the McAfee classification system (Grades 0 to 4 ) to classify heterotopic ossification (HO) [16]. McAfee grades $0-2$ were defined as low-grade $\mathrm{HO}$ and grades 3-4 as high-grade $\mathrm{HO}$, based on impaired ROM criteria [17]. Adjacent segment degeneration (ASD) was evaluated based on the narrowing of the disc space and new formation or enlargement of anterior osteophytes on lateral radiographs [18]. Prosthesis subsidence was defined as $>2 \mathrm{~mm}$ height loss of anterior or posterior functional spinal unit (FSU) when compared with that of the immediate postoperative radiograph.

\section{Statistical analysis}

Statistical analysis was performed using SPSS software version 19.0 (IBM SPSS Inc., New York, USA). The results were presented as mean \pm SD or percentages. A paired $\mathrm{t}$-test was used to compare preoperative and postoperative parameters. The independent $t$-test or the Mann-Whitney U test was used to compare continuous variables between the two groups. The Chi-square or Fisher's exact test was used for inter-group categorical variables. One-way ANOVA was used for continuous variables among the three surgical types. Tests were two-tailed with $p<0.05$.

\section{Results}

\section{Demographic data}

One hundred and 26 patients underwent 1-or 2-level surgery for a total of 132 arthroplasty segments (Table 1). Sixty-four (male/female: 32/32) were placed in the small-ROM group, and 62 (male/female: 21/41) in the large-ROM group, with a mean follow-up of 37.12 months. The mean age was 46.11 years in the small-ROM and 43.81 years in the largeROM groups. Sixty-one patients (48.41\%) underwent 1-level CDA, 26 (20.63\%) 2-level CDA, and 39 (30.96\%) 2-level HS. The most commonly operated level with CDA was C5/6 $(n=75)$, followed by $\mathrm{C} 4 / 5$ $(n=36)$, and then $\mathrm{C6} / 7 \quad(n=21)$. No patients underwent 2-level CDA distributed target levels in the different groups.

\section{Clinical outcomes}

Overall, JOA, NDI, and VAS scores showed significant post-surgical improvement $(P<0.001)$ in both the small-ROM and large-ROM groups. However, there were no significant differences in the JOA, NDI, and VAS scores between the two groups at any follow-up point (Table 2).

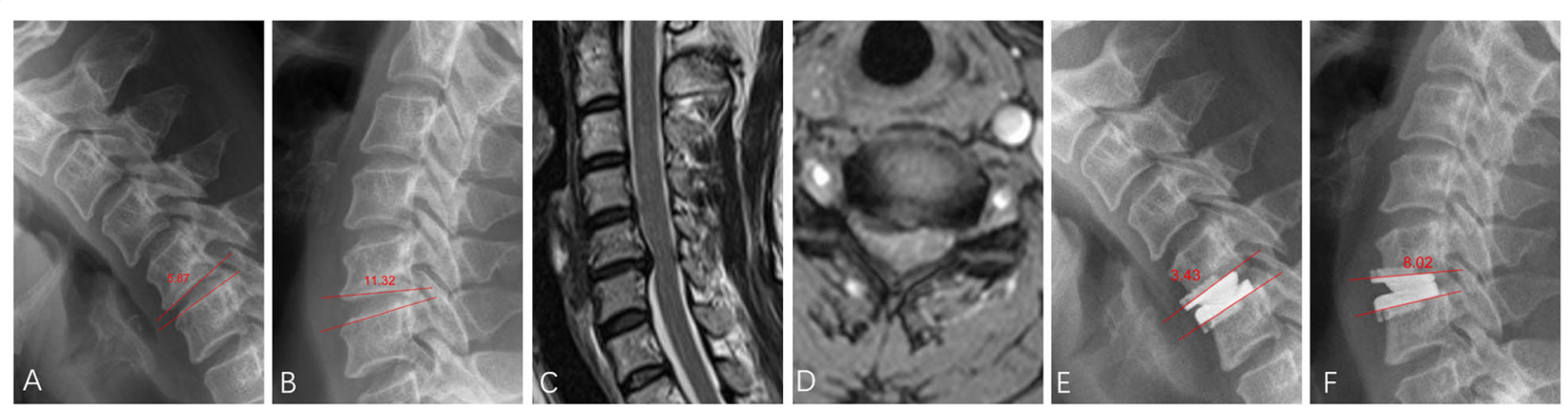

Fig. 2 A patient in the large-ROM group underwent CDA at C5/6 using Prestige-LP discs. Preoperative segmental ROM was measured at $17.19^{\circ}$ using lateral flexion-extension X-rays (a and $\mathbf{b}$ ), and MRI showed disc herniation at C5/6 (c and $\mathbf{d}$ ). The X-rays recorded at 50 months follow-up (e and $\mathbf{f}$ ) showing decreased segmental mobility $\left(\mathrm{ROM}=11.45^{\circ}\right)$ at the arthroplasty segment 
Table 1 Summary of the patient demographic data (Displayed as a number or mean \pm standard deviation)

\begin{tabular}{|c|c|c|c|}
\hline Variable & Small-ROM & Large-ROM & $P$ \\
\hline No. of patients, $n$ & 64 & 62 & - \\
\hline No. of arthroplasty levels, $n$ & 66 & 66 & - \\
\hline Age (range), years ${ }^{a}$ & $46.11 \pm 7.87(26-62)$ & $43.81 .58 \pm 7.99(28-63)$ & 0.106 \\
\hline $\operatorname{Sex}(M / F)^{c}$ & $32 / 32$ & $21 / 41$ & 0.067 \\
\hline $\mathrm{BMl}^{\mathrm{a}}$ & $23.67 \pm 2.87$ & $23.17 \pm 3.11$ & 0.354 \\
\hline T-value ${ }^{a}$ & $0.48 \pm 1.16$ & $0.45 \pm 1.26$ & 0.925 \\
\hline Cause $^{\mathrm{b}}$ & & & 0.051 \\
\hline Disc herniation & 43 & 53 & \\
\hline Spondylosis & 23 & 13 & \\
\hline Surgery type ${ }^{b}$ & & & 0.996 \\
\hline 1-level CDA & 31 & 30 & \\
\hline 2-level CDA & 14 & 13 & \\
\hline 2-level HS & 20 & 19 & \\
\hline Levels $^{\mathrm{b}}$ & & & 0.008 \\
\hline$C 4 / 5$ & 12 & 24 & \\
\hline$C 5 / 6$ & 38 & 37 & \\
\hline $\mathrm{C} 6 / 7$ & 16 & 5 & \\
\hline Operative time (range), $\min ^{a}$ & $131.83 \pm 36.95(60-225)$ & $135.29 \pm 38.53(60-300)$ & 0.608 \\
\hline Blood loss (range), mla & $56.11 \pm 33.47(5-150)$ & $66.69 \pm 58.94(10-350)$ & 0.216 \\
\hline Follow-up (range), months ${ }^{a}$ & $35.95 \pm 23.26(18-120)$ & $38.27 \pm 23.13(13-109)$ & 0.587 \\
\hline
\end{tabular}

andependent $\mathrm{t}$ test

${ }^{\mathrm{b}}$ Chi-square test

${ }^{\mathrm{c}}$ Fisher exact test

\section{Radiographic outcomes}

\section{Cervical lordosis and C2-C7 ROM}

The preoperative cervical lordosis values $\left(6.25^{\circ} \pm 11.24^{\circ}\right)$ had increased significantly at the last follow-up $\left(10.45^{\circ} \pm\right.$ $\left.7.90^{\circ}, P<0.001\right)$ for the small-ROM group, but changed slightly in the large-ROM group $\left(12.01^{\circ} \pm 12.62^{\circ}\right.$ vs. $\left.12.06^{\circ} \pm 9.08^{\circ}\right)$, respectively. Patients in the large-ROM group showed significantly larger cervical lordosis before

Table 2 Clinical outcomes between small-ROM and large-ROM groups

\begin{tabular}{llll}
\hline & Small-ROM & Large-ROM & $P$ \\
\hline JOA $^{\text {a }}$ & & & \\
Pre-op & $11.84 \pm 1.48$ & $11.85 \pm 1.46$ & 0.996 \\
$\begin{array}{c}\text { Post-op } \\
\text { NDI }^{a}\end{array}$ & $15.92 \pm 0.80$ & $15.84 \pm 0.79$ & 0.560 \\
Pre-op & $29.48 \pm 4.99$ & $28.15 \pm 3.37$ & \\
Post-op & $7.58 \pm 3.68$ & $7.77 \pm 3.39$ & 0.079 \\
VAS & & & 0.757 \\
Pre-op & $6.25 \pm 1.41$ & $6.29 \pm 1.25$ & 0.866 \\
Post-op & $1.39 \pm 1.06$ & $1.39 \pm 0.88$ & 0.984 \\
\hline
\end{tabular}

${ }^{\mathrm{a}}$ Independent $\mathrm{t}$ test

Pre-op Preoperatively, Post-op Postoperatively, JOA Japanese Orthopedic Association, NDI Neck Disability Index, VAS Visual Analogue Scale surgery $(P=0.008)$, but there was no significant postsurgical difference between the two groups. The overall cervical motion increased significantly from admission to the last follow-up in the small-ROM group $\left(37.85^{\circ} \pm\right.$ $13.51^{\circ}$ to $\left.45.38^{\circ} \pm 12.14^{\circ}, P<0.001\right)$ and significantly decreased in the large-ROM group $\left(59.79 \pm 11.79^{\circ}\right.$ to $\left.53.24^{\circ} \pm 12.56^{\circ}, P<0.001\right)$. The changes over the followup period are shown in Fig. 3 .

\section{Radiographic changes at the arthroplasty level}

The small-ROM group showed significantly less preoperative disc lordosis than the large- $\mathrm{ROM}$ group $\left(1.19^{\circ}\right.$ vs. $\left.4.09^{\circ}, P<0.001\right)$, and tended to have less reduction $\left(1.13^{\circ}\right.$ vs. $\left.2.14^{\circ}, P=0.125\right)$ at the last follow-up.

There was a significant increase in the preoperative $\left(4.05^{\circ} \pm 1.04^{\circ}\right.$ to $\left.7.11^{\circ} \pm 3.43^{\circ}\right)$ for the small-ROM group at the last follow-up, for an overall delta ROM $(\triangle \mathrm{ROM})$ of $3.05^{\circ} \pm 3.69^{\circ}(P<0.001$, Fig. 4$)$. The large-ROM group yielded an opposite trend; ROM of the arthroplasty level remarkably decreased from $14.80^{\circ} \pm 1.82^{\circ}$ to $10.02^{\circ} \pm$ $4.07^{\circ}$ with a $\triangle \mathrm{ROM}$ of $-4.77^{\circ} \pm 4.22^{\circ}(P<0.001$, Table $3)$. The segmental mobility was significantly higher in the large-ROM group, although the difference between the two groups was narrow $(P<0.001)$. The change of 


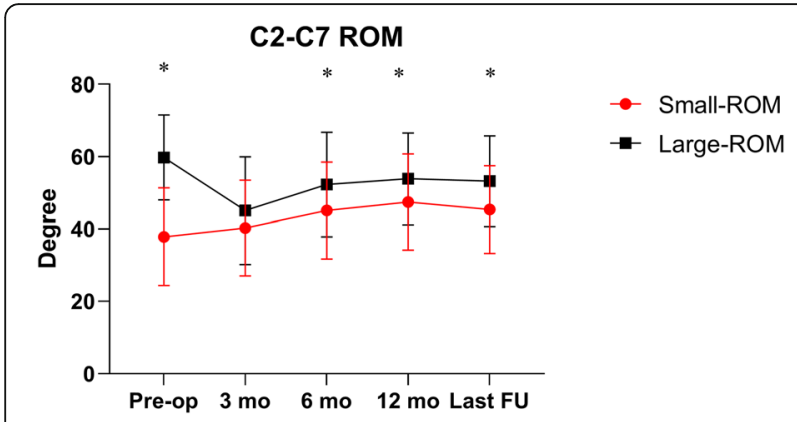

Fig. 3 C2-C7 ROM. Patients in the small-group showed a significant increase $(P<0.001)$ in $\mathrm{ROM}$, whereas those in the large-ROM group showed a significant decrease after surgery $(P<0.001)$. Asterisks $\left(^{*}\right)$ indicates a significant difference between the two groups $(P<0.05)$

segmental ROM at the arthroplasty level was similar for different surgical techniques (Table 4).

The average pre- and postoperative $\mathrm{DH}$ in the smallROM group were $5.22 \mathrm{~mm} \pm 0.81 \mathrm{~mm}$ and $6.40 \mathrm{~mm} \pm$ $0.70 \mathrm{~mm}$, respectively. The corresponding values in the large-ROM were $5.59 \mathrm{~mm} \pm 0.85 \mathrm{~mm}$ and $6.60 \mathrm{~mm} \pm$ $0.77 \mathrm{~mm}$, respectively. There was a significant difference in DH between the two groups preoperatively $(P=0.012)$.

\section{Complications}

Twelve patients (18.8\%) in the small-ROM and 10 $(16.1 \%)$ in the large-ROM group had degenerative radiographic changes (Table 3). The rate of HO development was significantly higher in the small-ROM than in the large-ROM group, as determined in the last follow-up $(60.6 \%$ vs. $42.4 \% . p=0.037)$. Although the proportion of high-grade $\mathrm{HO}$ levels was higher in the small-ROM as compared to the large-ROM group, the difference was not significant $(25.8 \%$ vs. $15.2 \%, P=0.131)$. We divided the arthroplasty levels into positive $\triangle \mathrm{ROM}(\mathrm{A})$ and a

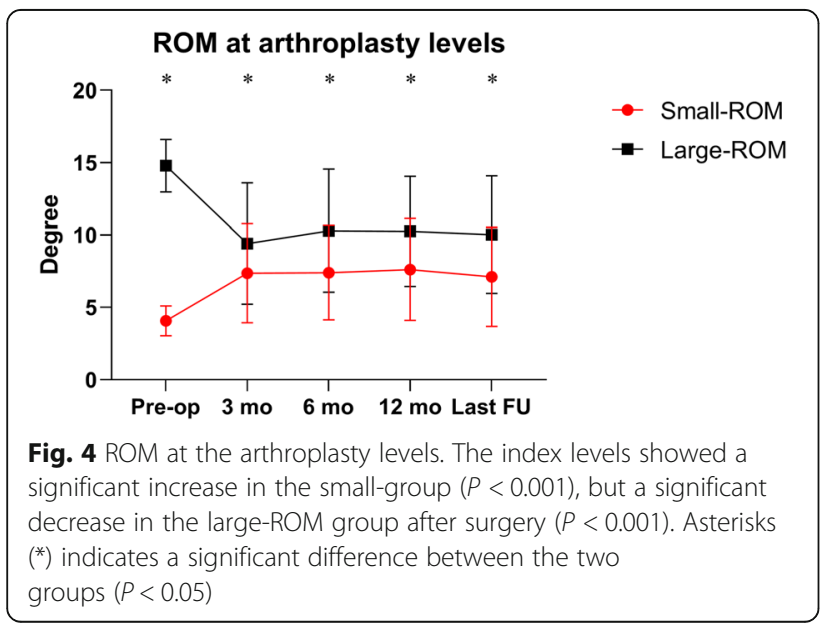

Table 3 Radiographic outcomes between small-ROM and largeROM groups

\begin{tabular}{|c|c|c|c|}
\hline & Small-ROM & Large-ROM & $P$ \\
\hline \multicolumn{4}{|l|}{$\overline{\text { Cervical lordosis }\left({ }^{\circ}\right)^{a}}$} \\
\hline Pre-op & $6.25 \pm 11.24$ & $12.01 \pm 12.62$ & 0.008 \\
\hline Post-op & $10.45 \pm 7.90$ & $12.06 \pm 9.08$ & 0.288 \\
\hline \multicolumn{4}{|l|}{$\mathrm{C} 2-\mathrm{C} 7 \mathrm{ROM}\left({ }^{\circ}\right)^{\mathrm{a}}$} \\
\hline Pre-op & $37.85 \pm 13.51$ & $59.79 \pm 11.79$ & $<0.001$ \\
\hline Post-op & $45.38 \pm 12.14$ & $53.24^{\circ} \pm 12.56^{\circ}$ & $<0.001$ \\
\hline$\triangle \mathrm{ROM}$ & $7.53 \pm 15.92^{\circ}$ & $-6.55^{\circ} \pm 13.48^{\circ}$ & $<0.001$ \\
\hline \multicolumn{4}{|l|}{ Disc angle $\left({ }^{\circ}\right)^{\mathrm{a}}$} \\
\hline Pre-op & $1.19 \pm 2.88$ & $4.09 \pm 4.09$ & $<0.001$ \\
\hline Post-op & $1.13 \pm 3.80$ & $2.13 \pm 3.75$ & 0.125 \\
\hline \multicolumn{4}{|l|}{ Segmental $\operatorname{ROM}\left(^{\circ}\right)^{a}$} \\
\hline Pre-op & $4.05 \pm 1.04$ & $14.80 \pm 1.82$ & $<0.001$ \\
\hline Post-op & $7.11 \pm 3.43$ & $10.02 \pm 4.07$ & $<0.001$ \\
\hline$\triangle \mathrm{ROM}$ & $3.05 \pm 3.69$ & $-4.77 \pm 4.22$ & $<0.001$ \\
\hline \multicolumn{4}{|l|}{ Disc height $(\mathrm{mm})^{a}$} \\
\hline Pre-op & $5.22 \pm 0.81$ & $5.59 \pm 0.85$ & 0.012 \\
\hline Post-op (immediately) & $6.40 \pm 0.70$ & $6.60 \pm 0.77$ & 0.368 \\
\hline$\Delta \mathrm{DH}$ & $1.18 \pm 0.73$ & $0.93 \pm 0.60$ & 0.034 \\
\hline $\operatorname{ASD}(\%)^{\mathrm{b}}$ & $12(18.8 \%)$ & $10(16.1 \%)$ & 0.698 \\
\hline HO formation (\%) ${ }^{b}$ & $40(60.6 \%)$ & $28(42.4 \%)$ & 0.037 \\
\hline HO classification (\%) & & & 0.131 \\
\hline Low-grade & 49 (74.2\%) & $56(84.8 \%)$ & \\
\hline High-grade & 17 (25.8\%) & $10(15.2 \%)$ & \\
\hline Subsidence $(\%)^{c}$ & 2 & 3 & 1.000 \\
\hline
\end{tabular}

Independent $\mathrm{t}$ test

${ }^{b}$ chi-square test

cFisher exact test

Pre-op Preoperatively, Post-op Postoperatively, ROM Range of motion, DH Disc height, ASD Adjacent segment degeneration, $\mathrm{HO}$ Heterotopic ossification

Table 4 Surgical type in relation to ROM in the Small-ROM and Large-ROM groups

\begin{tabular}{|c|c|c|c|c|}
\hline & 1-level CDA & 2-level CDA & 2-level HS & $P$ \\
\hline \multicolumn{5}{|c|}{ Small-ROM group } \\
\hline \multicolumn{5}{|c|}{ Segmental $\mathrm{ROM}\left({ }^{\circ}\right)^{\mathrm{a}}$} \\
\hline Pre-op & $4.04 \pm 1.02$ & $4.15 \pm 1.08$ & $4.00 \pm 1.07$ & 0.913 \\
\hline Post-op & $7.25 \pm 3.48$ & $6.49 \pm 3.34$ & $7.33 \pm 3.53$ & 0.735 \\
\hline$\triangle \mathrm{ROM}$ & $3.21 \pm 3.62$ & $2.34 \pm 3.61$ & $3.33 \pm 3.97$ & 0.699 \\
\hline
\end{tabular}

Large-ROM group

Segmental ROM $\left(^{\circ}\right)^{\text {a }}$

$\begin{array}{lllll}\text { Pre-op } & 14.47 \pm 1.33 & 15.15 \pm 2.06 & 14.99 \pm 2.24 & 0.406 \\ \text { Post-op } & 10.18 \pm 3.96 & 9.85 \pm 4.83 & 9.92 \pm 3.70 & 0.960 \\ \triangle \mathrm{ROM} & -4.29 \pm 3.97 & -5.30 \pm 4.02 & -5.06 \pm 4.87 & 0.695\end{array}$

${ }^{a}$ One-way ANOVA 

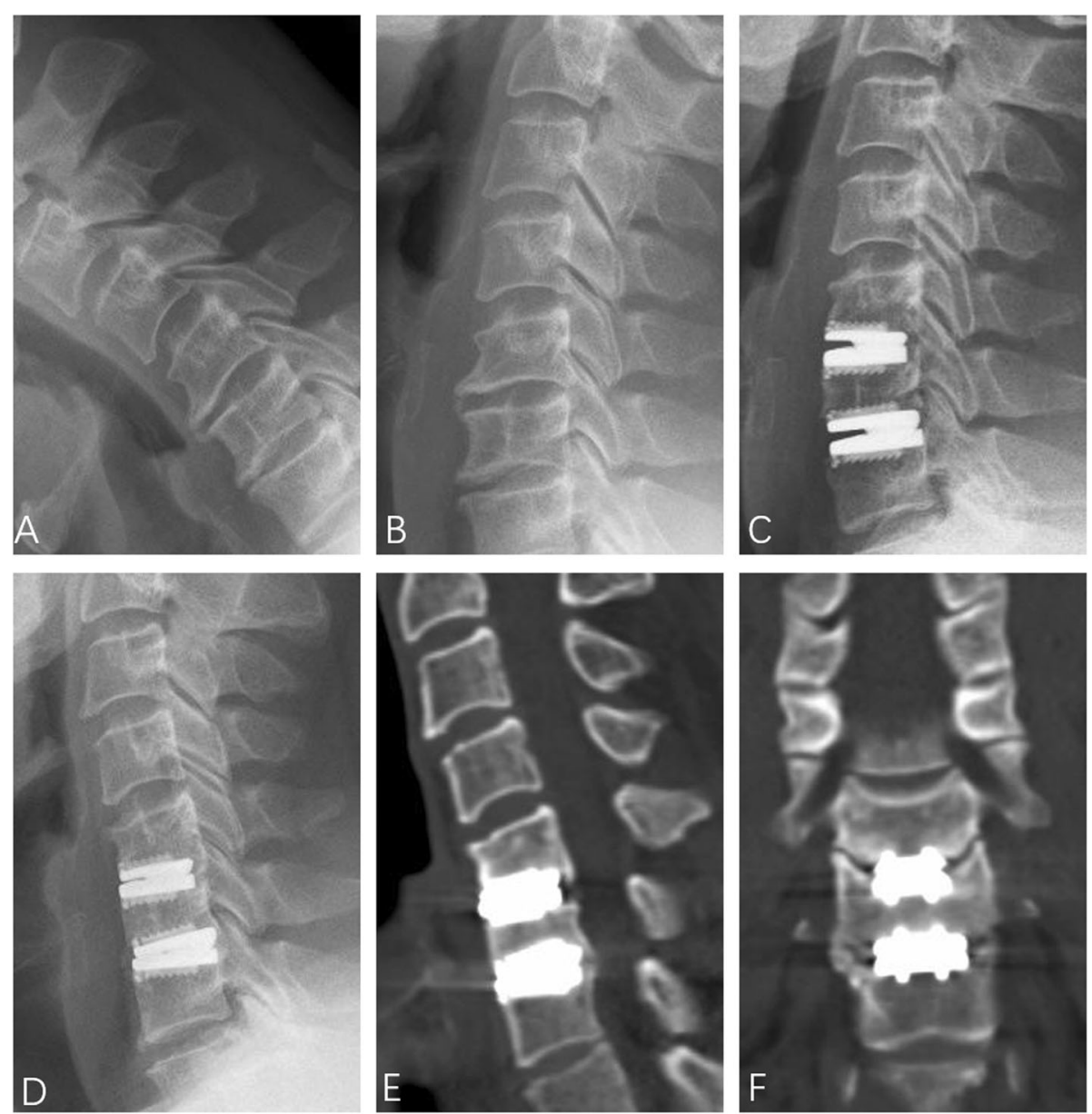

Fig. 5 A 43-year-old male patient diagnosed with cervical spondylosis. The preoperative ROMs at C5/6 and C6/7 were $4.28^{\circ}$ and $4.01^{\circ}$, respectively ( $(\mathbf{a}$ and $\mathbf{b})$. The immediate postoperative X-ray (c) demonstrated the satisfactory location of Prestige-LP discs. The 87-month X-ray (d) and $\mathrm{CT}$ scans (e and $\mathbf{f}$ ) showed the development of high-grade $\mathrm{HO}$ at C5/6 and C6/7

negative $\triangle$ ROM subgroups (B). Fourteen levels with less mobile $\left(\leq 5^{\circ}\right)$ were in subgroup B; however, 11 of them (78.6\%) developed high-grade HO (Fig. 5 and Table 5). Throughout the follow-up period, two levels in the small-ROM and 3 levels in the large-ROM group occurred subsidence. No device-related complications, such as screw loosening or prosthesis migration, occurred.

\section{Discussion}

Many trials have substantiated the theoretical advantages of CDA over fusion in recent decades, such as preservation of motion through the segments that were operated on; however, the documented ROM of CDA shows wide variability among patients. Several investigations suggest that the preoperative ROM scale is attributed to the variability of ROM after CDA [19], but there is a

Table 5 Subgroup analysis

\begin{tabular}{|c|c|c|c|c|c|c|}
\hline & \multicolumn{2}{|l|}{ Small-ROM } & \multirow[t]{2}{*}{$P$} & \multicolumn{2}{|l|}{ Large-ROM } & \multirow[t]{2}{*}{$P$} \\
\hline & $+\triangle \mathrm{ROM}$ & $-\triangle \mathrm{ROM}$ & & $+\triangle \mathrm{ROM}$ & $-\triangle \mathrm{ROM}$ & \\
\hline No. of arthroplasty levels & 52 & 14 & - & 10 & 56 & - \\
\hline HO formation (\%) ${ }^{a}$ & $28(53.8 \%)$ & $12(85.7 \%)$ & 0.035 & $3(30 \%)$ & $25(44.6 \%)$ & 0.498 \\
\hline HO classification (\%) & & & $<0.001$ & & & 0.338 \\
\hline Low-grade & $46(88.5 \%)$ & $3(21.4 \%)$ & & $10(100 \%)$ & $46(82.1 \%)$ & \\
\hline High-grade & $6(11.5)$ & $11(78.6 \%)$ & & 0 & $10(17.9 \%)$ & \\
\hline
\end{tabular}

${ }^{\mathrm{a}}$ Fisher exact test

HO Heterotopic ossification 
shortage of data on whether limited or excessive segmental mobility should be considered as a suitable indicator for CDA. In the current study, patients were divided into the small-ROM $\left(\mathrm{ROM} \leq 5.5^{\circ}\right)$ and largeROM $\left(>12.5^{\circ}\right)$ groups according to their preoperative index-level mobility. There was a significant difference in the distribution of operated levels between the groups, where $\mathrm{C} 4 / 5$ was more prone to hypermobility before surgery. This observation could be a reflection of the relatively spared disc disease at C4/5 compared with other segments [20,21]. There was post-surgical relief in patients' symptoms regardless of the preoperative segmental mobility; this may be due to the complete decompression of the spinal cord or nerve roots, disc height restoration and reconstructing stability of the cervical spine.

There was a difference in radiographic features between the small and large-ROM groups. Patients with limited segmental ROM showed significantly less global and segmental lordosis, ROM, and shorter DH. This may be due to the degenerative cascade concept; that loss of proteoglycans and water in the nucleus pulposus causes disc height loss, leading to excessive motion and instability at the early stage of disc degeneration and loss of segmental ROM at the late stage. These patients also suffered from relatively severe cervical spine degeneration. In the current study, we found that there was no significant difference in postoperative segmental ROM at the arthroplasty level among the three surgical types. The trends of segmental ROM did not alter regardless of the arthroplasty level adjacent to a fusion mass or a artificial disc. This result indicates that the change of ROM at each index level is relatively independent after surgery.

Disc with preoperatively limited ROM showed a significant increase in $\triangle \mathrm{ROM}$, by $3.05^{\circ}$, which parallels the observations of a previous study by Tu et al. [10]; however, unlike the current study, there were no clinical studies that had reported on CDA outcomes for discs with excessive motion. By contrast, the changes in ROM paradoxically decreased by $4.77^{\circ}$ in discs with preoperative hypermobility. Many factors, such as overstretch of the surrounding soft tissue [21], prostheses design [10], inconsistent axis of rotation [22], and development of HO [17], could lead to decreased ROM after CDA. These findings indicate that segmental ROM could be physiologically restored by CDA using Prestige-LP discs in some cases with loss of mobility, and that the technique could partly reduce mobility in some degenerative segments with excessive motion, to achieve "dynamic" re-stability.

The key concern for patients who had excessive preoperative ROM was that the associated hypermobility would cause increased stress loading on the facet joints and accelerate their degeneration, leading to additional neck pain. However, based on the clinical and radiographic outcomes, we observed that segmental mobility preservation at the index level and the maintenance of motion through the posterior elements did not place patients at risk of increased neck pain. Thus, we proposed that selected patients with preoperatively limited or excessive segmental ROM were good candidates for CDA.

Although there is no consensus on the mechanism of $\mathrm{HO}$, its development has been associated with variables such as age, sex, disc height, residual exposed endplate, and mismatch of the prosthesis [17, 23, 24]. We found that segments with preoperatively limited ROM has significantly less HO than those with excessive ROM at the last follow-up. This was in contrast to previous studies by $\mathrm{Tu}$ et al. [10], who reported that $\mathrm{HO}$ was similar for patients in the less-mobile and more-mobile groups. For further analysis, some segments in the negative $\triangle$ ROM subgroup were found to be more prone to severe $\mathrm{HO}$, especially those with preoperatively limited ROM. One explanation could be that limit-ROM discs inherently degenerated more before surgery. Zhou et al. [25] reported that patients with more severe preoperative cervical spondylosis had higher rates of ossification formation after CDA with Bryan discs. Wu et al. [26] demonstrated that patients diagnosed with soft-disc herniation had significantly less HO (6.25\%) than those diagnosed with spondylosis (58.33\%). In the current study, 11 segments with preoperatively limited ROM developed $\mathrm{HO}$ in the negative $\triangle \mathrm{ROM}$ subgroup; however, 8 of them (72.7\%) had been diagnosed with cervical spondylosis before surgery. This observation may indicate that patients with preoperative cervical spondylosis are not optimal candidates for CDA if the index-level ROM is limited.

There were several limitations to the study. First, it was retrospective and carried out at a single institution, presenting inherent weaknesses and limited generalizability of the findings. Second, we evaluated the disc-levels as long as they met the inclusion criteria before surgery. However, different surgery types or disclevels in the subaxial cervical spine may affect outcomes. The small sample size did not present adequatesubgroup data to cover all potential factors. In the current study, factors such as age, sex, and primary cause did not have any significant effect on the results, other than a tendency between the two groups, which may also attribute to the small sample size. Third, the study was limited to the Prestige-LP discs range of motion, whose FDA defined inclusion criterion of segmental ROM is $2^{\circ}-20^{\circ}$; thus, the results may not represent any other type of prostheses. Fourth, HO formation was a time-dependent complication after CDA. The results may not have been precisely evaluated due to the 
extensive period of the study and the relatively small sample of long-term follow-up cases.

\section{Conclusions}

Patients with preoperative limited segmental ROM had significantly severe postoperative $\mathrm{HO}$ and similar clinical improvents as patients with preoperative excessive segmental ROM. However, patients with preoperative limited segmental ROM showed increased postoperative segmental mobility, whereas patients with preoperative excessive segmental ROM paradoxically exhibited decreased postoperative segmental mobility. With proper patients selection, discs with limited or excessive mobility could benefit from CDA.

\section{Abbreviations \\ CDA: Cervical disc arthroplasty; ACDF: Anterior cervical discectomy and fusion; HS: Hybrid surgery; ASD: Adjacent segment degeneration; ROM: Range of motion; JOA: Japanese Orthopedics Association; NDI: Neck Disability Index; VAS: Visual Analogue Scale; DA: Disc angle; DH: Disc height; DDD: Degenerative disc disease; HO: Heterotopic ossification; CT: Computed tomography; MRI: Magnetic Resonance Imaging; SD: Standard deviation}

\section{Acknowledgements}

We would like to thank the people who assisted in this study.

\begin{abstract}
Authors' contributions
TKW and HL contributed to the design of the study. TKW drafted the manuscript with help from BYW, KKH, JBH, and YH. JBH and KKH helped in the statistical analyses. Statistical analysis was discussed with TKW, CD, and $\mathrm{HL}$. TKW, XR, and BYW contributed to the revision. The authors have read and approved the final manuscript.
\end{abstract}

\section{Funding}

This study was supported by the National Natural Science Foundation of China (31700839 and 81902190) and 1.3.5 project for disciplines of excellence, West China Hospital of Sichuan University (ZYJC18029).

\section{Availability of data and materials}

Summarized data has been presented in this manuscript. The raw data is located and protected at the West China Hospital of Sichuan University. Sharing of the raw data is not recommended, because a secondary analysis is planned.

\section{Ethics approval and consent to participate}

The study protocol was approved by the institutional ethics committee of West China Hospital of Sichuan University, and all patients signed informed consent.

\section{Consent for publication}

Not applicable.

\section{Competing interests}

The authors declare that they have no competing interests.

Received: 10 April 2020 Accepted: 12 June 2020

Published online: 13 July 2020

\section{References}

1. Lanman TH, Burkus JK, Dryer RG, Gornet MF, McConnell J, Hodges SD. Longterm clinical and radiographic outcomes of the Prestige LP artificial cervical disc replacement at 2 levels: results from a prospective randomized controlled clinical trial. J Neurosurg Spine. 2017;27(1):7-19.

2. Zhang X, Chen C, Zhang Y, Wang Z, Wang B, Yan W, et al. Randomized, controlled, multicenter, clinical trial comparing BRYAN cervical disc arthroplasty with anterior cervical decompression and fusion in China. Spine. 2012;37(6):433-8.
3. Skeppholm M, Lindgren L, Henriques T, Vavruch L, Lofgren H, Olerud C. The discover artificial disc replacement versus fusion in cervical radiculopathy--a randomized controlled outcome trial with 2-year follow-up. Spine J. 2015; 15(6):1284-94.

4. Phillips FM, Lee JY, Geisler FH, Cappuccino A, Chaput CD, DeVine JG, et al. A prospective, randomized, controlled clinical investigation comparing PCM cervical disc arthroplasty with anterior cervical discectomy and fusion. 2year results from the US FDA IDE clinical trial. Spine (Phila Pa 1976). 2013; 38(15):E907-18.

5. Murrey D, Janssen M, Delamarter R, Goldstein J, Zigler J, Tay B, et al. Results of the prospective, randomized, controlled multicenter Food and Drug Administration investigational, device exemption study of the ProDisc-C total disc replacement versus anterior discectomy and fusion for the treatment of 1-level symptomatic cervical disc disease. Spine J. 2009;9(4): $275-86$

6. Davis RJ, Kim KD, Hisey MS, Hoffman GA, Bae HW, Gaede SE, et al. Cervical total disc replacement with the Mobi-C cervical artificial disc compared with anterior discectomy and fusion for treatment of 2-level symptomatic degenerative disc disease: a prospective, randomized, controlled multicenter clinical trial: clinical article. J Neurosurg Spine. 2013;19(5):532-45.

7. Sasso RC, Smucker JD, Hacker RJ, Heller JG. Artificial disc versus fusion: a prospective, randomized study with 2-year follow-up on 99 patients. Spine (Phila Pa 1976). 2007;32(26):2965-9.

8. Gornet MF, Burkus JK, Shaffrey ME, Nian H, Harrell FE Jr. Cervical disc arthroplasty with Prestige LP disc versus anterior cervical discectomy and fusion: seven-year outcomes. Int J Spine Surg. 2016;10:24.

9. Gornet MF, Lanman TH, Burkus JK, Hodges SD, McConnell JR, Dryer RF, et al. Cervical disc arthroplasty with the Prestige LP disc versus anterior cervical discectomy and fusion, at 2 levels: results of a prospective, multicenter randomized controlled clinical trial at 24 months. J Neurosurg Spine. 2017; 26(6):653-67.

10. Tu TH, Lee CY, Kuo CH, Wu JC, Chang HK, Fay LY, et al. Cervical disc arthroplasty for less-mobile discs. J Neurosurg Spine. 2019;31(3):310-6.

11. Coric D, Cassis J, Carew JD, Boltes MO. Prospective study of cervical arthroplasty in 98 patients involved in 1 of 3 separate investigational device exemption studies from a single investigational site with a minimum 2-year follow-up. Clinical article. J Neurosurg Spine. 2010;13(6):715-21.

12. Obernauer J, Landscheidt J, Hartmann S, Schubert GA, Thome C, Lumenta C. Cervical arthroplasty with ROTAIO(R) cervical disc prosthesis: first clinical and radiographic outcome analysis in a multicenter prospective trial. BMC Musculoskelet Disord. 2016;17:11

13. Gornet MF, Burkus JK, Shaffrey ME, Argires PJ, Nian H, Harrell FE Jr. Cervical disc arthroplasty with PRESTIGE LP disc versus anterior cervical discectomy and fusion: a prospective, multicenter investigational device exemption study. J Neurosurg Spine. 2015;23(5):558-73.

14. Meisel HJ, Jurak L, Antinheimo J, Arregui R, Bruchmann B, Cabraja M, et al. Four-year results of a prospective single-arm study on 200 semi-constrained total cervical disc prostheses: clinical and radiographic outcome. J Neurosurg Spine. 2016;25(5):556-65.

15. Kang KC, Lee CS, Han JH, Chung SS. The factors that influence the postoperative segmental range of motion after cervical artificial disc replacement. Spine J. 2010;10(8):689-96.

16. McAfee PC, Cunningham BW, Devine J, Williams E, Yu-Yahiro J. Classification of heterotopic ossification $(\mathrm{HO})$ in artificial disk replacement. J Spinal Disord Tech. 2003;16(4):384-9.

17. Yang MMH, Ryu WHA, Casha S, DuPlessis S, Jacobs WB, Hurlbert RJ. Heterotopic ossification and radiographic adjacent-segment disease after cervical disc arthroplasty. J Neurosurg Spine. 2019;1-10. https://doi.org/10. 3171/2019.5.SPINE19257.

18. Goffin J, Geusens E, Vantomme N, Quintens E, Waerzeggers Y, Depreitere B, et al. Long-term follow-up after interbody fusion of the cervical spine. J Spinal Disord Tech. 2004;17(2):79-85.

19. Kim SW, Paik SH, Castro PA, Baek SW, Shin DJ, Kwak YH, et al. Analysis of factors that may influence range of motion after cervical disc arthroplasty. Spine J. 2010;10(8):683-8.

20. Park JJMD, Quirno MMD, Cunningham MRMD, Schwarzkopf RMD, Bendo JAMD, Spivak JMMD, et al. Analysis of segmental cervical spine vertebral motion after Prodisc-C cervical disc replacement. Spine. 2010;35(8):E285-9.

21. Peng CWB, Quirnoa M, Bendo JA, Spivak JM, Goldstein JA. Effect of intervertebral disc height on postoperative motion and clinical outcomes after Prodisc-C cervical disc replacement. Spine J. 2009;9(7):551-5. 
22. Hu $X$, Jiang $M$, Liu $H$, Rong $X$, Hong $Y$, Ding $C$, et al. Five-year trends in Center of Rotation after single-level cervical arthroplasty with the PrestigeLP disc. World Neurosurg. 2019;132:e941-8.

23. Zeng J, Liu H, Chen $H$, Rong $X$, Meng $Y$, Yang $Y$, et al. Effect of prosthesis width and depth on heterotopic ossification after cervical disc arthroplasty. Spine (Phila Pa 1976). 2019;44(9):624-8.

24. Yi S, Shin DA, Kim KN, Choi G, Shin HC, Kim KS, et al. The predisposing factors for the heterotopic ossification after cervical artificial disc replacement. Spine J. 2013;13(9):1048-54.

25. Zhou F, Ju KL, Zhao Y, Zhang F, Pan S, Heller JG, et al. Progressive bone formation after cervical disc replacement: minimum of 5-year follow-up. Spine (Phila Pa 1976). 2018;43(3):E163-e170.

26. Wu JC, Huang WC, Tu TH, Tsai HW, Ko CC, Wu CL, et al. Differences between soft-disc herniation and spondylosis in cervical arthroplasty: $C T$ documented heterotopic ossification with minimum 2 years of follow-up. J Neurosurg Spine. 2012;16(2):163-71.

\section{Publisher's Note}

Springer Nature remains neutral with regard to jurisdictional claims in published maps and institutional affiliations.

Ready to submit your research? Choose BMC and benefit from:

- fast, convenient online submission

- thorough peer review by experienced researchers in your field

- rapid publication on acceptance

- support for research data, including large and complex data types

- gold Open Access which fosters wider collaboration and increased citations

- maximum visibility for your research: over $100 \mathrm{M}$ website views per year

At BMC, research is always in progress.

Learn more biomedcentral.com/submissions 